\title{
Traumatic Brain Injury and Risk of Dementia and Alzheimer's Disease: A Systematic Review and Meta-Analysis
}

\author{
Dongqing $\mathrm{Gu}^{\mathrm{a}}$ Shan $\mathrm{Ou}^{\mathrm{b}}$ Guodong Liu ${ }^{\mathrm{c}}$ \\ aDepartment of Epidemiology and Biostatistics, First Affiliated Hospital, Army Medical University, Chongqing, China; \\ ${ }^{b}$ Department of Anesthesiology, First People's Hospital of Chengdu, Chengdu, China; 'The Eighth Department, \\ State Key Laboratory of Trauma, Burns and Combined Injury, Research Institute of Surgery, Daping Hospital, Army \\ Medical University, Chongqing, China
}

\section{Keywords}

Traumatic brain injury · Dementia · Alzheimer's disease ·

Association · Meta-analysis

\begin{abstract}
Introduction: Previous studies have investigated the potential role of traumatic brain injury (TBI) in subsequent development of dementia and Alzheimer's disease (AD) but reported inconsistent results. We aimed to determine the association between TBI and subsequent occurrence of dementia and AD. Methods: We performed a systematic search in PubMed and Web of Science for studies that quantitatively investigated the association between TBI and risk of dementia and AD and were published on or before September 21, 2021. A random-effects model was used to combine the estimates. Results: Twenty-five eligible articles were included in this meta-analysis. The results suggested that TBI was associated with an increased risk of dementia (pooled odds ratio $[\mathrm{OR}]=1.81,95 \%$ confidence interval $[\mathrm{Cl}]$ = 1.53-2.14). However, no association was observed between $\mathrm{TBI}$ and $\mathrm{AD}$ (pooled $\mathrm{OR}=1.02,95 \% \mathrm{Cl}=0.91-1.15$ ). In the subgroup analysis, TBI with loss of consciousness was not associated with risk of dementia (pooled OR $=0.96,95 \%$
\end{abstract}

karger@karger.com www.karger.com/ned

Karger $\stackrel{\text { ' }}{5}$

GOPEN ACCESS
(C) 2021 The Author(s)

Published by S. Karger AG, Basel

This is an Open Access article licensed under the Creative Commons Attribution-NonCommercial-4.0 International License (CC BY-NC) (http://www.karger.com/Services/OpenAccessLicense), applicable to the online version of the article only. Usage and distribution for commercial purposes requires written permission.
$\mathrm{Cl}=0.84-1.09$ ). Besides, Asian ethnicity, male gender, and mean age of the participants less than 65 years were associated with a higher risk of dementia. Conclusion: Our study suggests an increased risk of dementia among individuals with TBI, highlighting the need for more intensive medical monitoring and health education in individuals with TBI. Biological mechanisms linking TBI and the development of dementia are needed in future studies.

(C) 2021 The Author(s) Published by S. Karger AG, Basel

\section{Introduction}

Traumatic brain injury (TBI) is the most common cause of death and disability worldwide, with various long-term outcomes in survivors [1]. Approximately, 23 million adults aged more than 40 years reported a history of TBI with loss of consciousness (LOC); in the USA alone, TBI cases grow by an alarming rate of 1.7 million annually [2-5]. The personal and societal costs are estimated to be USD 400 billion worldwide, accounting for $0.5 \%$ of the entire annual global output $[6,7]$. In addition, higher rates of morbidity and mortality are seen in low-income and middle-income countries, making it a global health challenge [2]. 
Indeed, TBI is the most frequent cause of nervous tissue damage in the developed countries [8]. Neurological damage may occur not only at the moment of impact (primary injury) of TBI but also over patients' lifetime (secondary injury) [9]. Secondary damage is often linked to the molecular mechanisms that occur following TBI and results in neurotransmitter release, calcium-mediated damage, gene activation, mitochondrial dysfunction, excitotoxicity, neuroinflammation and cytokine damage, oxidative damage, and eventual cell death [10-12]. Interestingly, epidemiological evidence also showed correlation of TBI with an increased risk of neurodegenerative disease such as dementia [13-15], Alzheimer's disease (AD) [16-18], multiple sclerosis [19-21], Parkinson's disease [22-24], and amyotrophic lateral sclerosis [2527].

As the most common neurodegenerative disorder, $\mathrm{AD}$ is the most common cause of dementia in old age [28]. It was reported that all-cause dementia risk was increased by around 1.5 times, of which, around $5 \%$ of all dementia cases worldwide may be attributable to TBI [29]. In particular, there is a long history linking TBI with the development of dementia, and an increasing number of articles have been published to explore the relationship between TBI and risk of dementia and $\mathrm{AD}$ in recent years. However, despite significant reservations, such as recall bias or concluding causality for TBI, the results were not all consistent. Several observational studies have suggested that TBI was associated with an increased risk of dementia or $\mathrm{AD}[14,30]$, whereas others reported no association [31,32].

In addition, Perry et al. [33] and Huang et al. [9] conducted meta-analyses but found no association between TBI and dementia or AD. Since most of the included studies in these meta-analyses were not cohort but casecontrol studies, the results might be confounded by various factors such as recall bias and selection bias. Besides, the exposure was yet a more broad head-injury definition, and the exposure assessment in these included studies was mainly based on self-report or questionnaire, making the effects stronger. Therefore, we performed an up-todate meta-analysis to reevaluate this association based on published studies so as to determine whether TBI was a risk factor of dementia or AD.

\section{Methods}

This meta-analysis was performed according to the guidelines proposed by the PRISMA statement and Meta-analysis Of Observational Studies in Epidemiology [34, 35].

Traumatic Brain Injury and Dementia

\section{Literature Search}

A comprehensive literature search of related studies was conducted using PubMed and Web of Science (published on or before September 21, 2021), with the following keywords "Alzheimer's disease or Alzheimer disease or dementia" and "Traumatic brain injury or craniocerebral trauma or craniocerebral injury" as query terms. The title and abstract of studies or the full text if necessary was reviewed to identify all relevant publications. In addition, reference lists of all included studies as well as reviews and metaanalyses were manually screened for extra potential studies.

\section{Inclusion and Exclusion Criteria}

Inclusion criteria were as follows: (1) cohort studies, case-control studies, or cross-sectional studies that quantitatively investigated the association between TBI and risk of dementia or AD; (2) exposure to TBI defined based on medical records, military records, questionnaires, or self-reports; (3) the outcome of interest was dementia or AD; (4) providing risk estimates with $95 \%$ confidence interval (CI) or data to calculate them; and (5) published in the English language. Exclusion criteria were as follows: (1) abstracts, reviews, letters, case reports, and studies that did not provide sufficient data to calculate the risk estimates and (2) exposure to head injury or head trauma which was not clearly defined as TBI. Two investigators independently selected studies, and any discrepancy was resolved through discussion.

\section{Data Extraction and Quality Assessment}

Data extraction was completed independently by two investigators, and any discrepancy was resolved by the third investigator. The following information was extracted from each study: first author, year of publication, country, ethnicity, study design, data source, exposure, assessment method of exposure, outcome, assessment method of outcome, the number of cases, the number of controls or sample size for cohort studies, odds ratio (OR), relative risk, hazard ratio (HR), or standardized incidence ratio and corresponding 95\% CI. For each study, the fully adjusted risk estimates were extracted, and the age-adjusted risk estimates or univariate risk estimates and adjustments were used when the multivariate risk estimates were unavailable.

Quality assessment was performed using the Newcastle-Ottawa Scale (NOS) [36]. Individual studies were assessed based on three quality parameters: selection, comparability, and outcome. The maximum total score is nine points, with a score of seven points or higher indicating high study quality.

\section{Statistical Analysis}

Statistical analyses were done using Stata version 15 (Stata, College Station, TX, USA), and two-sided $p$ values of 0.05 or less were considered statistically significant unless otherwise stated. Associations between TBI and risk of dementia and AD were evaluated by pooled OR and corresponding 95\% CI using a random-effects model (DerSimonian-Laird) [37]. The significance of pooled OR was determined by the $Z$ test.

Evaluation of meta-analysis included the test of heterogeneity, sensitivity analyses, and publication bias. The statistical heterogeneity among the studies was assessed by the Cochran Q statistic ( $p$ values $<0.10$ was considered indicative of statistically significant heterogeneity) and $I^{2}$ statistic ( $I^{2}$ values less than $25 \%$ represented mild heterogeneity, values between $25 \%$ and $50 \%$ represented moderate heterogeneity, and values greater than $50 \%$ represented 


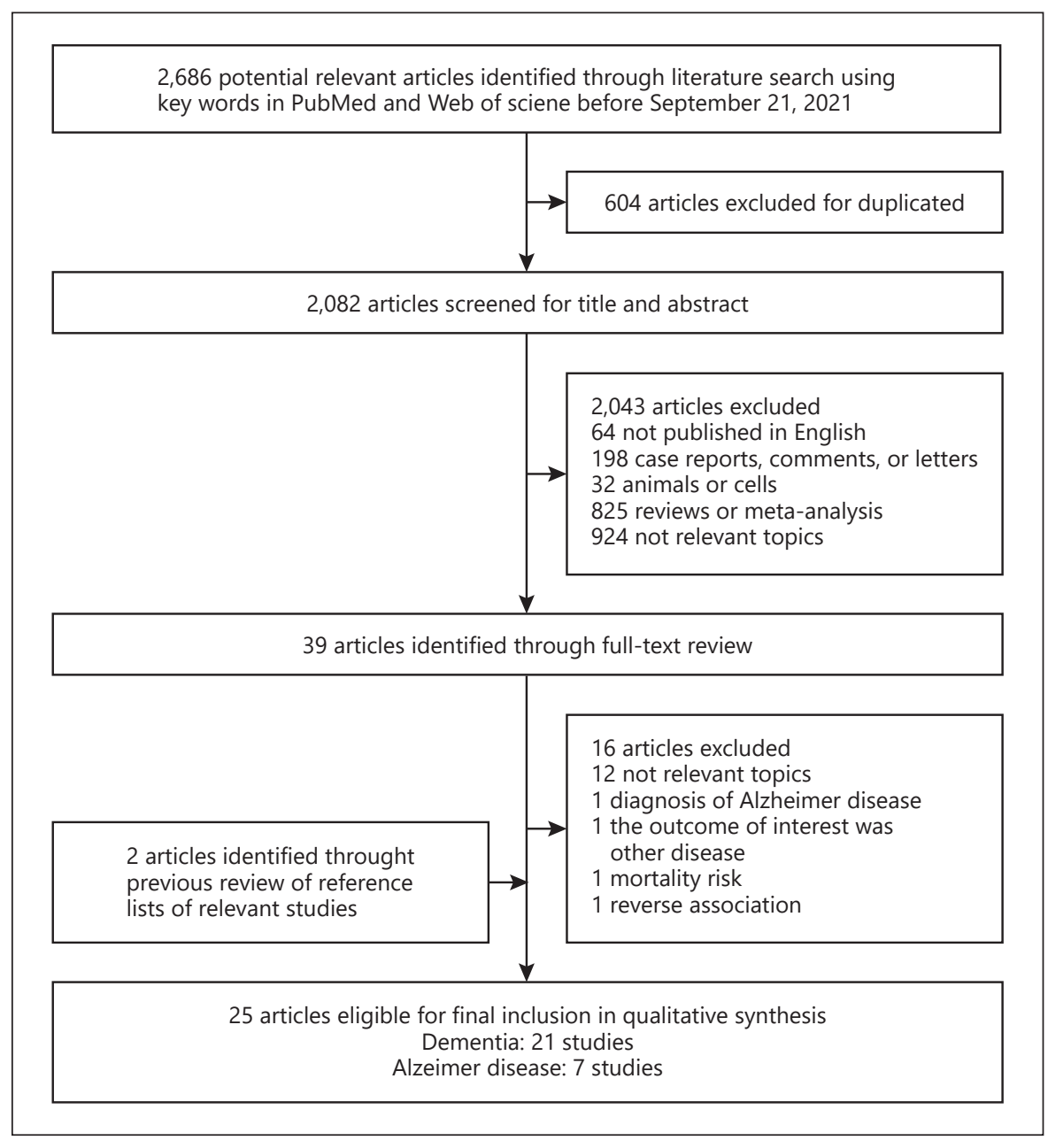

Fig. 1. Literature search flowchart.

large heterogeneity) $[38,39]$. In addition, sensitivity analyses were performed to investigate the influences of single studies on the overall risk estimate by removing one study each time. The potential publication bias was evaluated using both Begg's test and Egger's test, and $p$ values $<0.10$ were considered to be statistically significant $[40,41]$.

\section{Results}

\section{Literature Search Results and Study Characteristics}

The literature search and selection process are presented in Figure 1. The comprehensive search generated 2,686 potentially relevant articles. After excluding 604 duplicated articles, we reviewed the title and abstract of 2,082 articles and excluded 2,043 of them. Then, full texts of the remaining 39 studies were examined, and we excluded 16 of them. To be specific, 12 articles with irrelevant topics, one article about the diagnosis of $\mathrm{AD}$, one article about the mortality risk in patients with TBI, one article in which the outcome of interest was TBI, and one article in which the outcome of interest was other disease were excluded. Additionally, two articles were included through previous review or reference lists of relevant studies. Finally, 25 articles met our inclusion criteria and were included in the meta-analysis, including 23 cohort studies [14, 15, 30-32, 42-59] and two case-control studies $[60,61]$.

The characteristics of the included studies are summarized in Table 1. Of these studies, 21 articles investigated the association between TBI and dementia with a total sample size of 8,684,485 and 411,310 cases, and seven articles investigated the association between TBI and AD with a total sample size of 2,820,181 and 11,487 cases. Among these studies, 14 were conducted in USA, six in Europe (two in Sweden, two in Denmark, one in the UK, and one in Finland), four in China, and one in Austria. TBI ascertainment was mainly based on International Classification of Diseases codes (68\%). In addition, each 


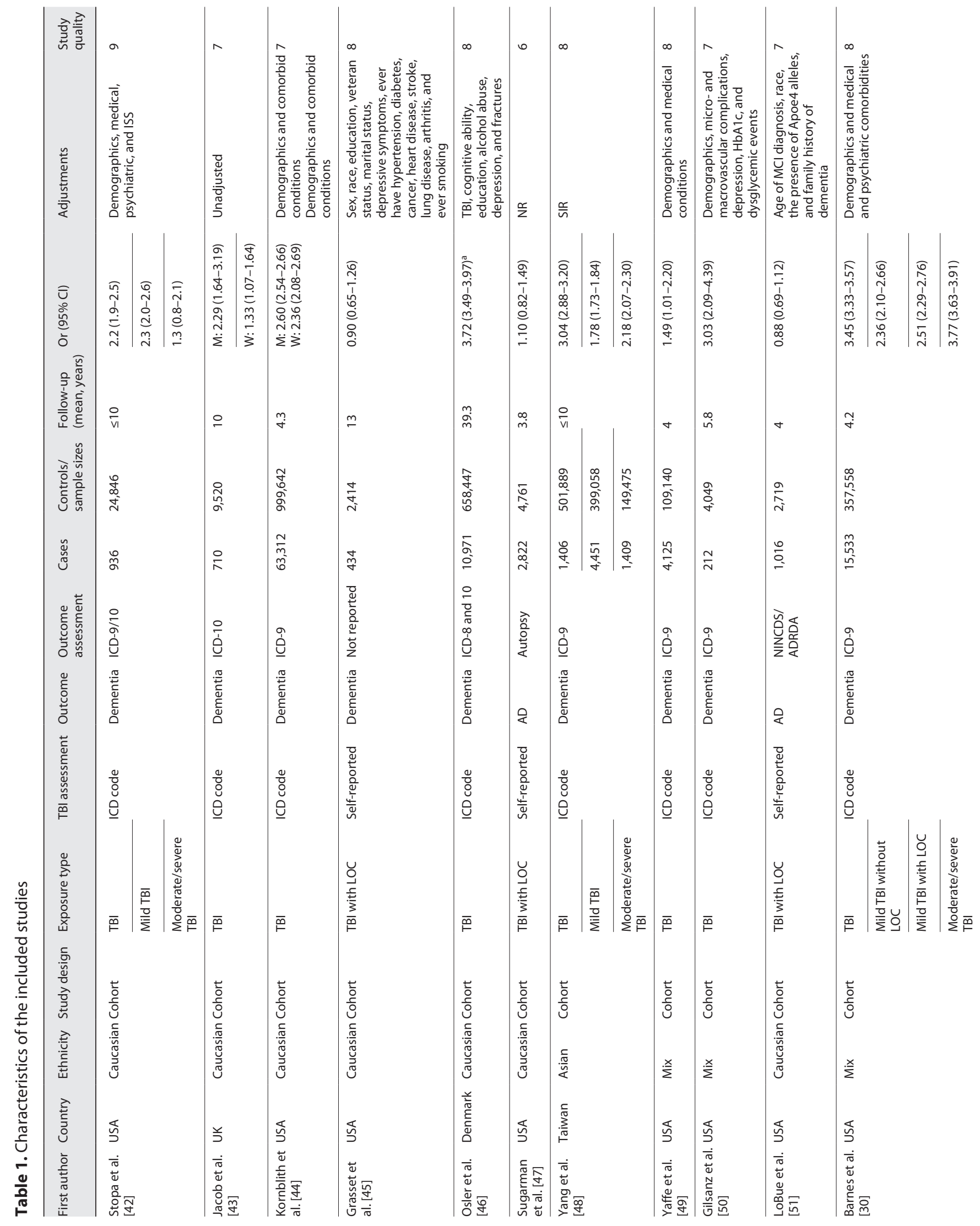




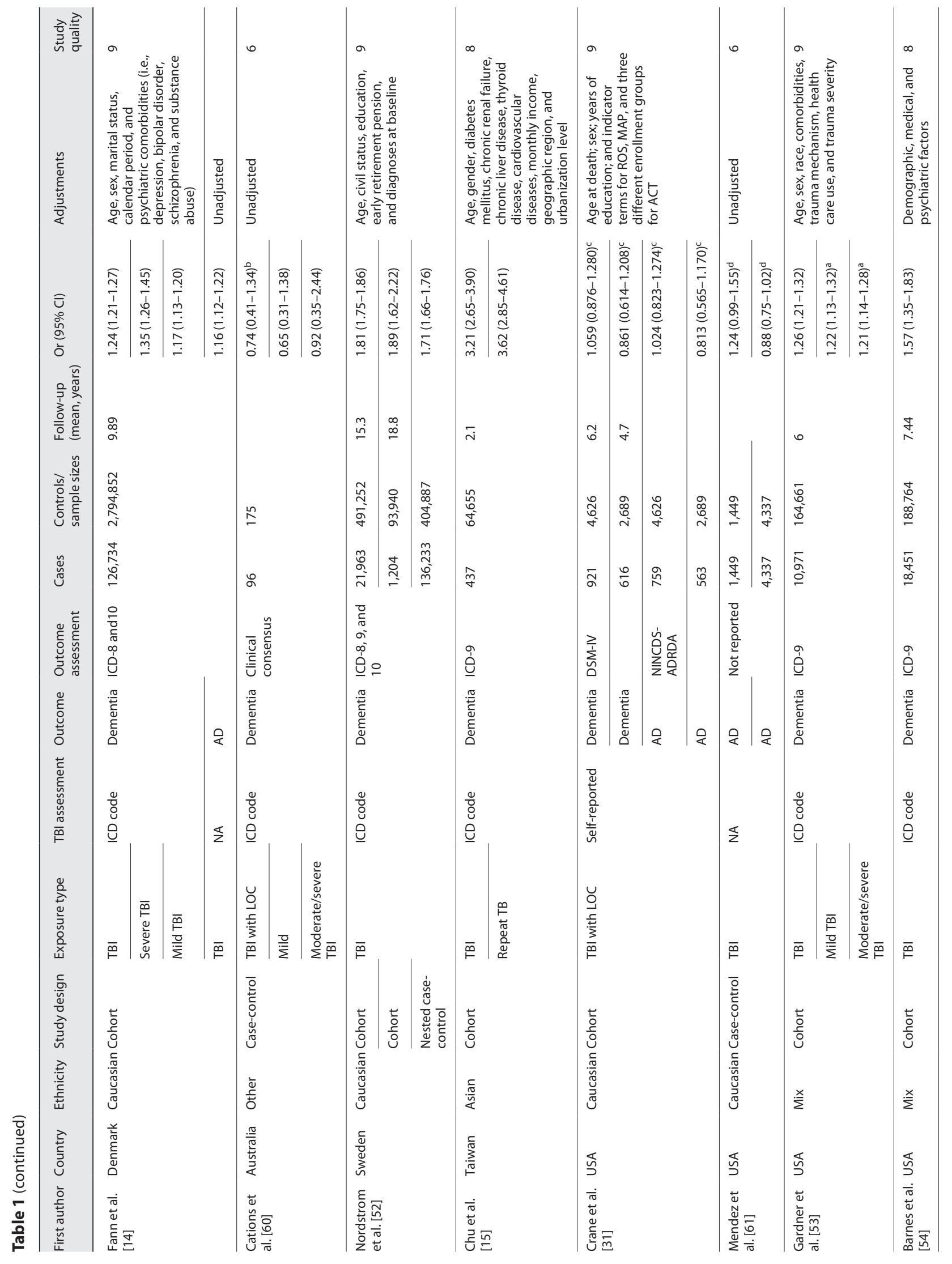




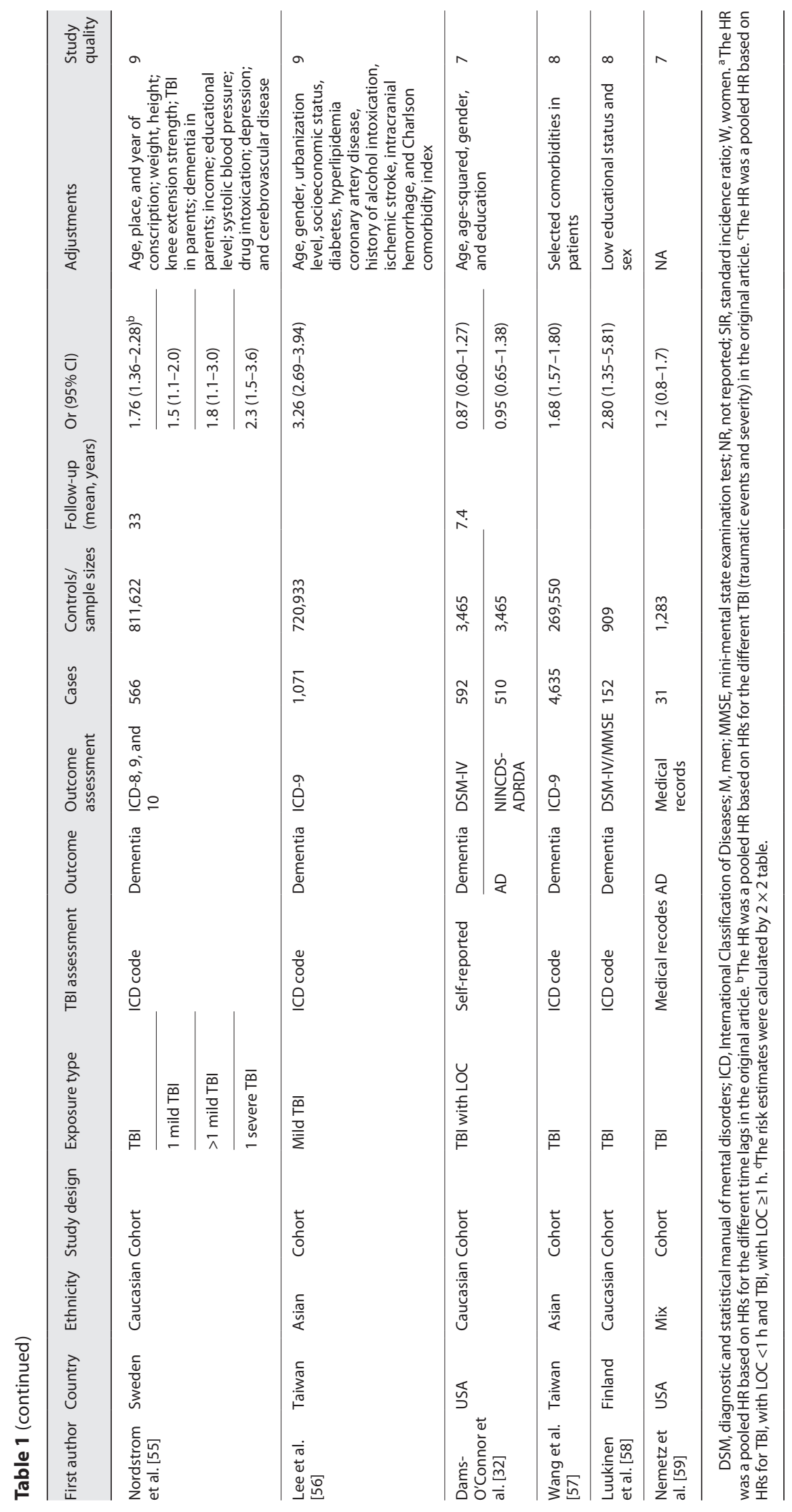




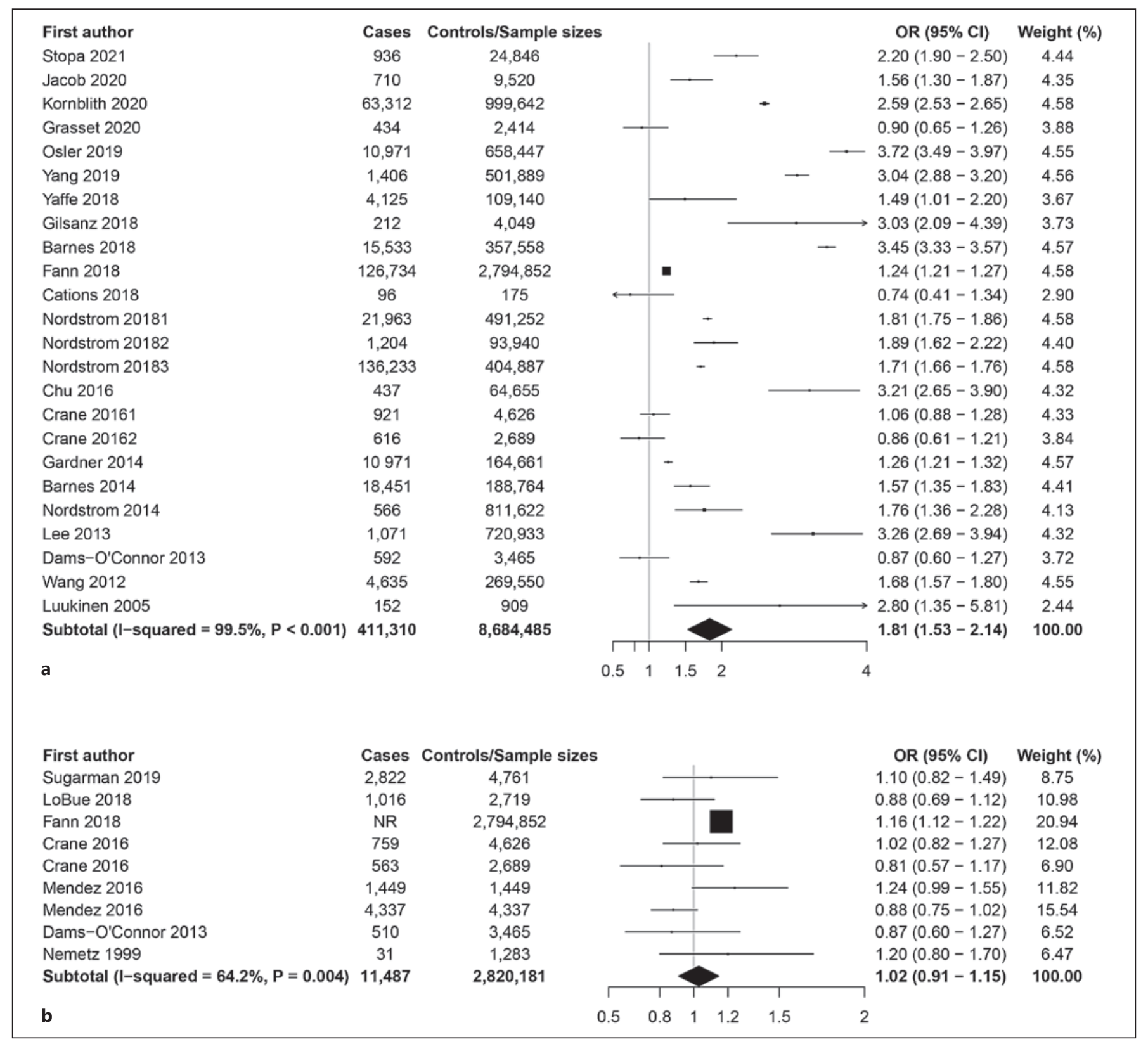

Fig. 2. Forest plots of TBI and risk of dementia and AD. a TBI and risk of dementia. $\mathbf{b}$ TBI and risk of AD.

study included in our meta-analysis was carefully assessed according to the NOS. The quality scores ranged from 6 to 9 points, and 22 studies $(88 \%)$ were scored 7 points or higher, indicating high quality.

\section{Association between TBI and Risk of Dementia and $A D$}

We found a moderate association between TBI and risk of dementia (pooled $\mathrm{OR}=1.81,95 \% \mathrm{CI}=1.53-2.14$ ), whereas no association was observed between TBI and $\mathrm{AD}$ risk (pooled $\mathrm{OR}=1.02,95 \% \mathrm{CI}=0.91-1.15)$ (Fig. 2). In the subgroup analyses, TBI with LOC was not associated with risk of dementia (pooled $\mathrm{OR}=0.96,95 \% \mathrm{CI}=$ 0.84-1.09). Besides, we found that Asian ethnicity (pooled $\mathrm{OR}=2.69,95 \% \mathrm{CI}=1.84-3.94)$, male gender (pooled OR $=2.05,95 \% \mathrm{CI}=1.43-2.95)$, and mean age less than 65 years (pooled $\mathrm{OR}=2.13,95 \% \mathrm{CI}=1.63-2.78$ ) were associated with higher risk of dementia (Fig. 3).
10
$\mathrm{Gu} / \mathrm{Ou} / \mathrm{Liu}$ 


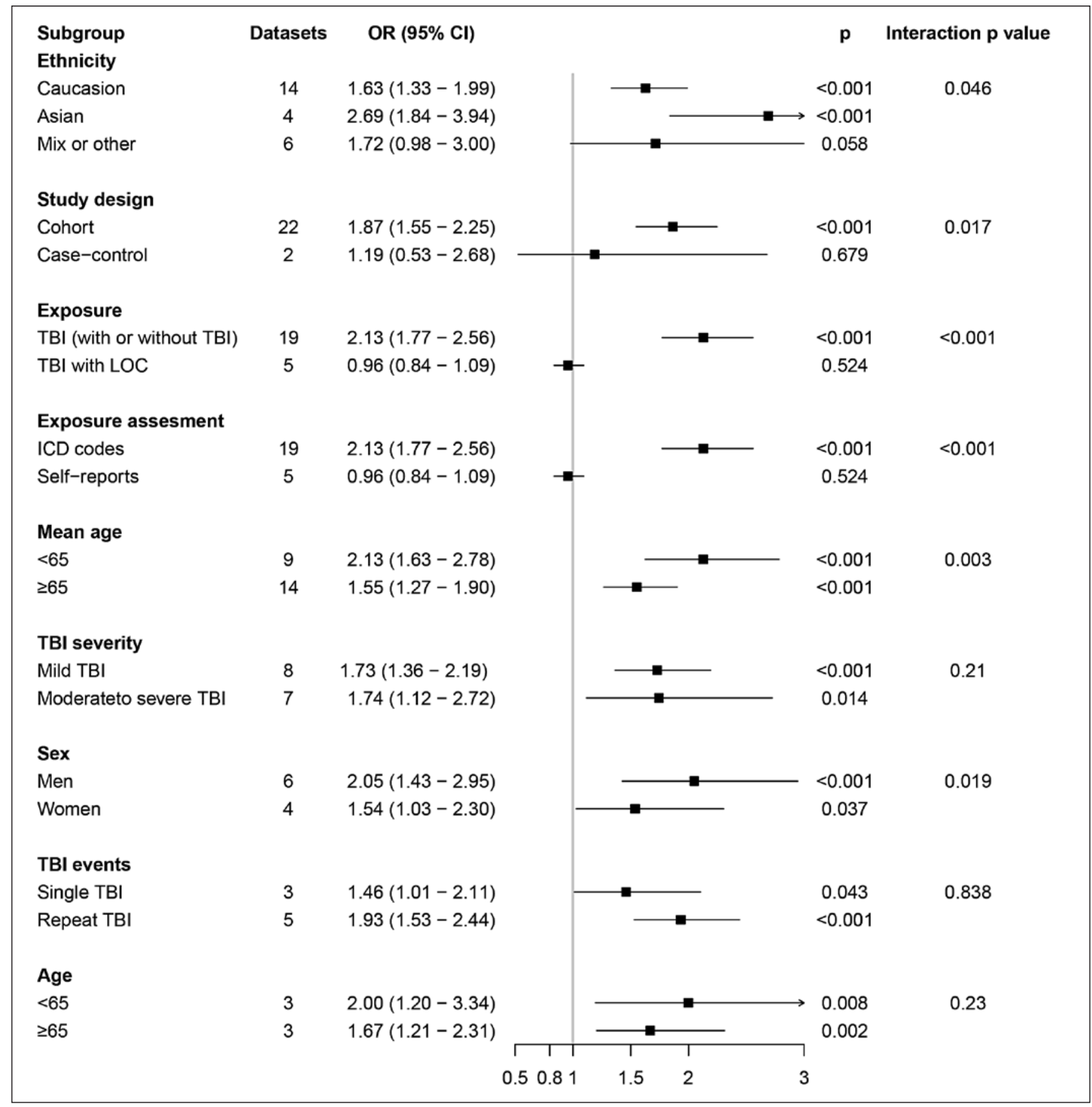

Fig. 3. Subgroup analyses for risk of dementia in individuals with TBI.

Heterogeneity, Sensitivity Analysis, and Publication

Bias

Large heterogeneity was found among studies concerning relationship between TBI and risk of dementia $\left(I^{2}=99.5 \%, p<0.001\right)$ and $\mathrm{AD}\left(I^{2}=64.2 \%, p=0.004\right)$.
Meta-regression analyses suggested that study design $(p=0.017)$, ethnicity $(p=0.046)$, exposure variable $(p$ $<0.001)$, and mean age of the participants $(p=0.003)$ might be the potential sources of heterogeneity of TBI and dementia risk $(p=0.001)$. Sensitivity analysis was 
Fig. 4. Sensitivity analyses. a Dementia. b AD.
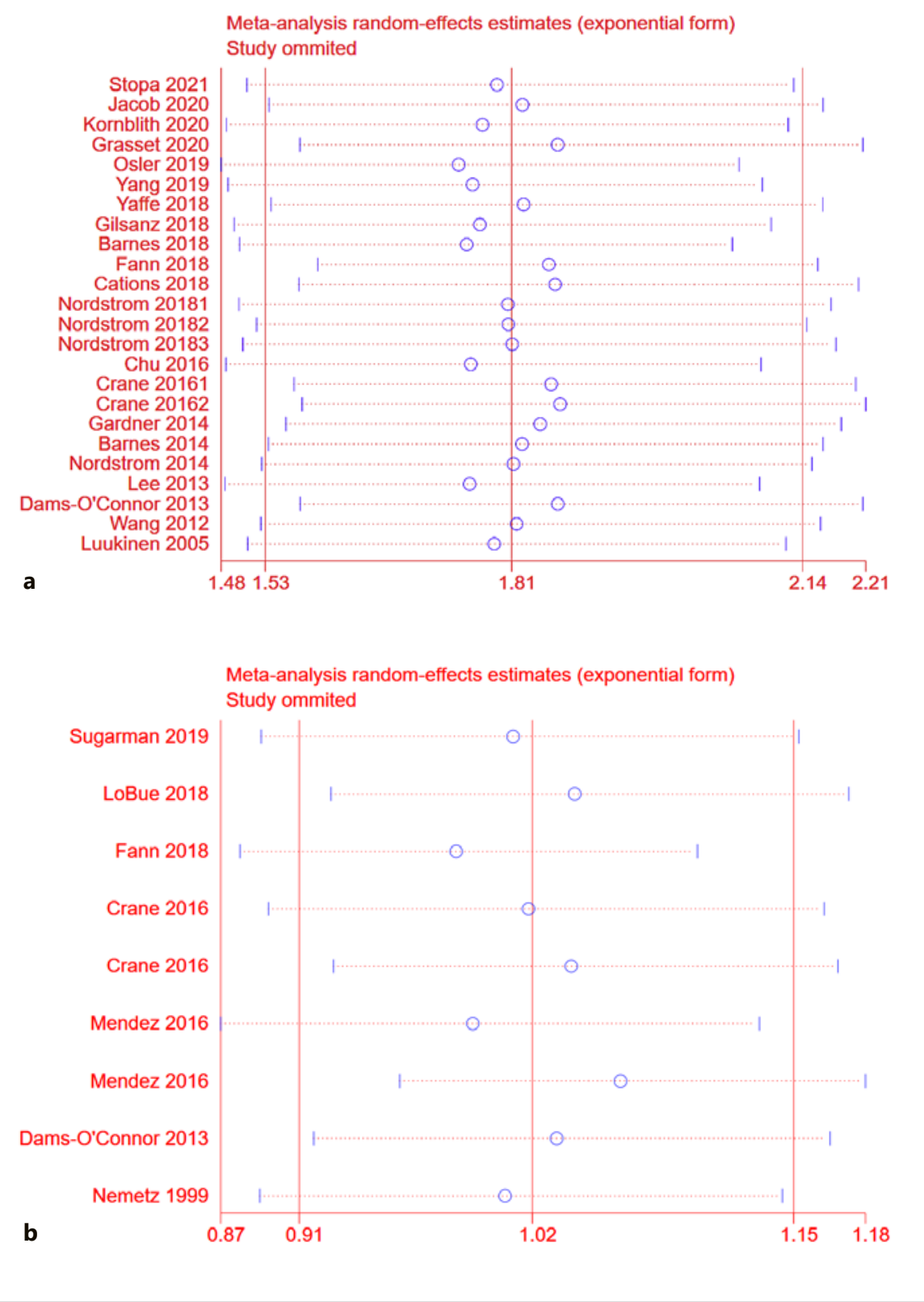

performed to evaluate the stability of results and showed that removing any single study could not significantly change the pooled relative risks and 95\% CIs (Fig. 4). In addition, the funnel plot seemed symmetrical according to visual inspection (Fig. 5). Begg's test $(p=0.941)$ and Egger's test $(p=0.985)$ further confirmed that there was no potential publication bias in our meta-analysis.

\section{Discussion}

Our analysis comprehensively evaluated the relationship between TBI and subsequent risks of dementia and $\mathrm{AD}$. The results suggested that TBI was associated with an increased risk of subsequent dementia, especially in individuals with Asian ethnicity, male gender, and mean age less than 65 years. We believe that these findings will highlight the need for more intensive medical monitoring 


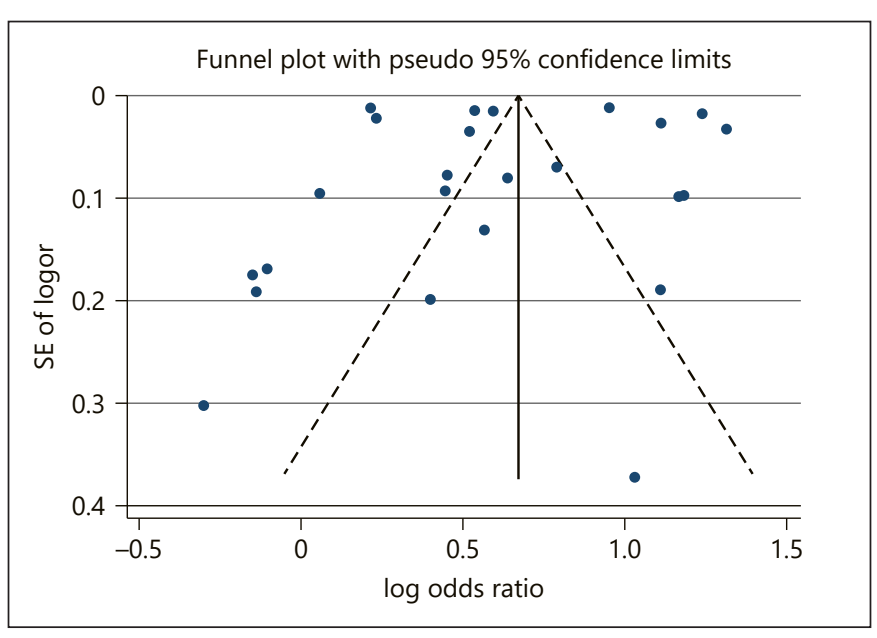

Fig. 5. Funnel plots.

and health education in patients with TBI. From a public health perspective, TBI prevention programs can help reduce the burden of dementia worldwide.

In this study, we found that TBI was associated with a 1.81 -fold increased risk of dementia, which was consistent with previous meta-analyses and recent large cohort studies [9, 16, 30, 46, 48-50]. Possible mechanisms have been proposed to explain the positive association between TBI and dementia risk. It has been hypothesized that dysfunction of the blood-brain barrier might play a critical role in pathogenesis of dementia [62]. TBI can disrupt the blood-brain barrier, which could cause leukocyte infiltration and microglial activation. Besides, mitochondrial function, $\beta$-amyloid pathology, chronic neuroinflammation, tau deposition, vascular damage, and white-matter degeneration in patients with TBI have been implicated in development of neurodegenerative disease [63-70].

In our study, the risk of dementia was significantly elevated in patients with TBI. However, no association was found between TBI and subsequent AD. Alternatively, TBI may trigger a neuropathological process that more directly leads to dementia. Several studies have suggested that TBI-related dementia is distinct from AD both in the clinical presentation and the associated neuropathology [71]. Chronic traumatic encephalopathy, which is attributed to repeated head trauma, has become widely accepted to describe dementia syndrome [72, 73]. The neuropathology of chronic traumatic encephalopathy was reported to be different from the neuropathology of $\mathrm{AD}$ [74]. Otherwise, TBI was reported to be a risk factor of frontotemporal degeneration, which is one of the leading causes of neurodegenerative dementia [54, 75].

Traumatic Brain Injury and Dementia
Nevertheless, our meta-analysis included not only cohort studies but also case-control studies. Therefore, subgroup analysis by the study design was conducted to explore the potential resource of heterogeneity. Pooled results from different study deigns were inconsistent, which may cause biases. Results from case-control studies could have been somewhat biased by selective participation of TBI, and the information about TBI was recorded after dementia diagnosis, so the results might be confounded by recall bias.

In addition, we conducted subgroup analyses to determine whether TBI characteristics or methodological factors would influence our findings. Although TBI with LOC had no significant association with dementia, there were very limited studies on TBI with or without the LOC subgroup, making the subgroup results lack statistical power. Otherwise, our study suggested a comparable risk of dementia in patients with mild TBI or moderate to severe TBI. Therefore, whether the severity of TBI was associated with dementia was a puzzle. The assessment methods for TBI may also vary between the included studies, and the assessment of TBI in several included studies was based on a self-report, which could induce recall bias, especially for the patients with dementia or $\mathrm{AD}$.

It is known that older age was a risk factor of dementia. Interestingly, we found a higher increased risk of dementia in TBI patients with a mean age less than 65 years compared with those older than 65 years (pooled OR: 2.13 vs. $1.55, p=0.003$ ), which may be explained by a couple of factors according to a previous study that reported dementia risk as the greatest in the middle-aged patients with TBI [42]. Although subgroup analysis by ethnicity suggested that TBI-related risk was higher in Asian populations, the data sources were all generated from a single database of Taiwan. Therefore, the participants may be largely overlapped, leading to overestimation of this association. Another important result of this study is the association between TBI and dementia differing between men and women. TBI-associated risk of dementia was higher (pooled OR: 2.05 vs. $1.54, p=0.019$ ) in men compared with women, and the results were similar with previous meta-analysis and recent nationwide cohort studies $[14,43,76,77]$.

Several limitations in this meta-analysis warrant consideration. First, many retrospective studies were included in our study; therefore, the results might be influenced by recall bias or selective bias. Besides, five studies included in our study reported unadjusted risk estimates, which could be confounded by other variables such as age and 
gender. Second, although no evidence supports a positive association between TBI and AD in this study, the results should be explained with caution. On the one hand, the studies claiming to examine risk of $\mathrm{AD}$ specifically were often unadjusted. On the other hand, the outcome ascertainment of $\mathrm{AD}$ was usually different in the included studies (i.e., one autopsy study, a few relying on International Classification of Diseases codes, and the rest using National Institute of Neurological and Communicative Diseases and Stroke-Alzheimer Disease and Related Disorders Association (NINCDS-ADRDA) for outcome ascertainment), and the risk of misascertainment (or at the very least, inconsistent ascertainment) of the outcome in the AD studies. Indeed, exact examination of all-case dementia and $\mathrm{AD}$ was needed since $\mathrm{AD}$ was in fact the cause of the dementia. Third, we could hardly perform subgroup analysis of TBI and $\mathrm{AD}$ due to the available data. Finally, although Begg's and Egger's tests confirmed no potential publication bias in our meta-analysis, there was potential publication bias since only English language studies were included in this study.

In conclusion, the current meta-analysis has confirmed that TBI is a potential risk factor for dementia, especially in individuals of Asian ethnicity, male gender, and mean age less than 65 years. Although no evidence supports a positive association between $\mathrm{TBI}$ and $\mathrm{AD}$ in this study, more well-designed studies with exact examination of all-case dementia and $\mathrm{AD}$ are needed to examine their relationship in the future.

\section{Statement of Ethics}

An ethics statement is not applicable because this study is based exclusively on the published literature.

\section{Conflict of Interest Statement}

The authors have no conflicts of interest to declare.

\section{Funding Sources}

This study was funded by China Postdoctoral Science Foundations (2014M562594, 2015T81090), the Military Biosafety Project (no.19SWAQ18), and the Postdoctoral Science Foundation of Chongqing (Xm2015034).

\section{Author Contributions}

G.L. and D.G. contributed to the conception and design of the study. D.G. and S.O. did the literature search, data extraction, and quality assessment. G.L. and D.G. did statistical analysis. D.G. wrote the first draft of the original manuscript with significant contributions from S.O. and G.L. All the authors read and approved the final manuscript.

\section{Data Availability Statement}

All data generated or analyzed during this study are included in this article. Further inquiries can be directed to the corresponding author.

\section{References}

1 Wang K, Cui D, Gao L. Traumatic brain injury: a review of characteristics, molecular basis and management. Front Biosci. 2016;21: $890-9$.

2 Khellaf A, Khan DZ, Helmy A. Recent advances in traumatic brain injury. J Neurol. 2019;266(11):2878-89.

3 Schneider ALC, Wang D, Ling G, Gottesman RF, Selvin E. Prevalence of self-reported head injury in the United States. N Engl J Med. 2018;379(12):1176-8.

4 Robertson IH. Traumatic brain injury: recovery, prediction, and the clinician. Arch Phys Med Rehabil. 2008;89(12 Suppl):S1-2. .

5 Park E, Bell JD, Baker AJ. Traumatic brain injury: can the consequences be stopped? CMAJ. 2008;178(9):1163-70.

6 Maas AIR, Menon DK, Adelson PD, Andelic N, Bell MJ, Belli A, et al. Traumatic brain injury: integrated approaches to improve prevention, clinical care, and research. Lancet Neurol. 2017;16(12):987-1048.
7 McMillan TM, Teasdale GM, Weir CJ, Stewart E. Death after head injury: the 13 year outcome of a case control study. J Neurol Neurosurg Psychiatry. 2011;82(8):931-5.

8 Pupillo E, Poloni M, Bianchi E, Giussani G, Logroscino G, Zoccolella S, et al. Trauma and amyotrophic lateral sclerosis: a european population-based case-control study from the EURALS consortium. Amyotroph Lateral Scler Frontotemporal Degener. 2018;19(1-2): 118-25.

9 Huang $\mathrm{CH}$, Lin $\mathrm{CW}$, Lee YC, Huang CY, Huang RY, Tai YC, et al. Is traumatic brain injury a risk factor for neurodegeneration? A meta-analysis of population-based studies. BMC Neurol. 2018;18(1):184.

10 Ladak AA, Enam SA, Ibrahim MT. A review of the molecular mechanisms of traumatic brain injury. World Neurosurg. 2019;131: 126-32.
11 Corps KN, Roth TL, McGavern DB. Inflammation and neuroprotection in traumatic brain injury. JAMA Neurol. 2015;72(3):355-62.

12 Huisman TA, Poretti A. Trauma. Handb Clin Neurol. 2016;136:1199-220.

13 Radford K, Lavrencic LM, Delbaere K, Draper B, Cumming R, Daylight G, et al. Factors associated with the high prevalence of dementia in older aboriginal australians. J Alzheimers Dis. 2019;70(s1):S75-S85.

14 Fann JR, Ribe AR, Pedersen HS, Fenger-Gron $\mathrm{M}$, Christensen J, Benros ME, et al. Long-term risk of dementia among people with traumatic brain injury in Denmark: a populationbased observational cohort study. Lancet Psychiatry. 2018;5(5):424-31.

15 Chu SF, Chiu WT, Lin HW, Chiang YH, Liou TH. Hazard ratio and repeat injury for dementia in patients with and without a history of traumatic brain injury: a population-based secondary data analysis in Taiwan. Asia Pac J Public Health. 2016;28(6):519-27. 
16 Li Y, Li Y, Li X, Zhang S, Zhao J, Zhu X, et al. Head Injury as a risk factor for dementia and Alzheimer's disease: a systematic review and meta-analysis of 32 observational studies. PLoS One. 2017;12(1):e0169650.

17 Abner EL, Nelson PT, Schmitt FA, Browning SR, Fardo DW, Wan L, et al. Self-reported head injury and risk of late-life impairment and $\mathrm{AD}$ pathology in an $\mathrm{AD}$ center cohort. Dement Geriatr Cogn Disord. 2014;37(5-6): 294-306.

18 Tolppanen AM, Taipale H, Hartikainen S. Head or brain injuries and Alzheimer's disease: a nested case-control register study. Alzheimers Dement. 2017;13(12):1371-9.

19 Abbasi M, Nabavi SM, Fereshtehnejad SM, Jou NZ, Ansari I, Shayegannejad V, et al. Multiple sclerosis and environmental risk factors: a case-control study in Iran. Neurol Sci. 2017; 38(11):1941-51.

20 Al-Afasy HH, Al-Obaidan MA, Al-Ansari YA, Al-Yatama SA, Al-Rukaibi MS, Makki NI, et al. Risk factors for multiple sclerosis in Kuwait: a population-based case-control study. Neuroepidemiology. 2013;40(1):30-5.

21 Kang JH, Lin HC. Increased risk of multiple sclerosis after traumatic brain injury: a nationwide population-based study. J Neurotrauma. 2012;29(1):90-5.

22 Gardner RC, Byers AL, Barnes DE, Li Y, Boscardin J, Yaffe K. Mild TBI and risk of Parkinson disease: a chronic effects of neurotrauma consortium study. Neurology. 2018;90(20): e1771-9.

23 Camacho-Soto A, Warden MN, Searles Nielsen S, Salter A, Brody DL, Prather H, et al. Traumatic brain injury in the prodromal period of Parkinson's disease: a large epidemiological study using medicare data. Ann Neurol. 2017;82(5):744-54.

24 Chen CY, Hung HJ, Chang KH, Hsu CY, Muo $\mathrm{CH}$, Tsai $\mathrm{CH}$, et al. Long-term exposure to air pollution and the incidence of Parkinson's disease: a nested case-control study. PLoS One. 2017;12(8):e0182834.

25 Filippini T, Fiore M, Tesauro M, Malagoli C, Consonni M, Violi F, et al. Clinical and lifestyle factors and risk of amyotrophic lateral sclerosis: a population-based case-control study. Int J Environ Res Public Health. 2020 Jan 30;17(3):857.

26 Tsai CP, Hu C, Lee CT. Finding diseases associated with amyotrophic lateral sclerosis: a total population-based case-control study. Amyotroph Lateral Scler Frontotemporal Degener. 2019;20(1-2):82-9.

27 Lian L, Liu M, Cui L, Guan Y, Liu T, Cui B, et al. Environmental risk factors and amyotrophic lateral sclerosis (ALS): a case-control study of ALS in China. J Clin Neurosci. 2019; 66:12-8.

28 Ballard C, Gauthier S, Corbett A, Brayne C, Aarsland D, Jones E. Alzheimer's disease. Lancet. 2011;377(9770):1019-31.

29 Graham NS, Sharp DJ. Understanding neurodegeneration after traumatic brain injury: from mechanisms to clinical trials in demen- tia. J Neurol Neurosurg Psychiatry. 2019; 90(11):1221-33.

30 Barnes DE, Byers AL, Gardner RC, Seal KH, Boscardin WJ, Yaffe K. Association of mild traumatic brain injury with and without loss of consciousness with dementia in US military veterans. JAMA Neurol. 2018;75(9): 1055-61.

31 Crane PK, Gibbons LE, Dams-O’Connor K, Trittschuh E, Leverenz JB, Keene CD, et al. Association of traumatic brain injury with late-life neurodegenerative conditions and neuropathologic findings. JAMA Neurol. 2016;73(9):1062-9.

32 Dams-O'Connor K, Gibbons LE, Bowen JD, McCurry SM, Larson EB, Crane PK. Risk for late-life re-injury, dementia and death among individuals with traumatic brain injury: a population-based study. J Neurol Neurosurg Psychiatry. 2013;84(2):177-82.

33 Perry DC, Sturm VE, Peterson MJ, Pieper CF, Bullock T, Boeve BF, et al. Association of traumatic brain injury with subsequent neurological and psychiatric disease: a meta-analysis. J Neurosurg. 2016;124(2):511-26.

34 Moher D, Liberati A, Tetzlaff J, Altman DG, Group P. Preferred reporting items for systematic reviews and meta-analyses: the PRISMA statement. BMJ. 2009;339:b2535.

35 Stroup DF, Berlin JA, Morton SC, Olkin I, Williamson GD, Rennie D, et al. Meta-analysis of observational studies in epidemiology: a proposal for reporting. Meta-analysis $\mathrm{Of} \mathrm{Ob}-$ servational Studies in Epidemiology (MOOSE) group. JAMA. 2000;283(15):2008-12.

36 Stang A. Critical evaluation of the newcastleOttawa scale for the assessment of the quality of nonrandomized studies in meta-analyses. Eur J Epidemiol. 2010;25(9):603-5.

37 DerSimonian R, Laird N. Meta-analysis in clinical trials. Control Clin Trials. 1986;7(3): $177-88$.

38 Lau J, Ioannidis JP, Schmid CH. Quantitative synthesis in systematic reviews. Ann Intern Med. 1997;127(9):820-6.

39 Higgins JP, Thompson SG. Quantifying heterogeneity in a meta-analysis. Stat Med. 2002; 21(11):1539-58.

40 Egger M, Davey Smith G, Schneider M, Minder C. Bias in meta-analysis detected by a simple, graphical test. BMJ. 1997;315(7109):62934.

41 Begg CB, Mazumdar M. Operating characteristics of a rank correlation test for publication bias. Biometrics. 1994;50(4):1088-101.

42 Stopa BM, Tahir Z, Mezzalira E, Boaro A, Khawaja A, Grashow R, et al. The impact of age and severity on dementia after traumatic brain injury: a comparison study. Neurosurgery. 2021 Oct 13;89(5):810-18.

43 Jacob L, Azouvi P, Kostev K. Age-related changes in the association between traumatic brain injury and dementia in older men and women. J Head Trauma Rehabil. 2021 MayJun 01;36(3):E139-E46.

44 Kornblith E, Peltz CB, Xia F, Plassman B, Novakovic-Apopain T, Yaffe K. Sex, race, and risk of dementia diagnosis after traumatic brain injury among older veterans. Neurology. 2020;95(13):e1768-75.

45 Grasset L, Glymour MM, Yaffe K, Swift SL, Gianattasio KZ, Power MC, et al. Association of traumatic brain injury with dementia and memory decline in older adults in the United States. Alzheimers Dement. 2020;16(6):85361.

46 Osler M, Rozing MP, Eliasen MH, Christensen K, Mortensen EL. Traumatic brain injury and risk of dementia at different levels of cognitive ability and education. Eur J Neurol. 2020;27(2):399-405.

47 Sugarman MA, McKee AC, Stein TD, Tripodis Y, Besser LM, Martin B, et al. Failure to detect an association between self-reported traumatic brain injury and Alzheimer's disease neuropathology and dementia. Alzheimers Dement. 2019;15(5):686-98.

48 Yang JR, Kuo CF, Chung TT, Liao HT. Increased risk of dementia in patients with craniofacial trauma: a nationwide populationbased cohort study. World Neurosurg. 2019; 125:e563-74. .

49 Yaffe K, Lwi SJ, Hoang TD, Xia F, Barnes DE, Maguen S, et al. Military-related risk factors in female veterans and risk of dementia. Neurology. 2019;92(3):e205-11.

50 Gilsanz P, Albers K, Beeri MS, Karter AJ, Quesenberry CP Jr., Whitmer RA. Traumatic brain injury associated with dementia risk among people with type 1 diabetes. Neurology. 2018;91(17):e1611-8.

51 LoBue C, Woon FL, Rossetti HC, Hynan LS, Hart J, Cullum CM. Traumatic brain injury history and progression from mild cognitive impairment to Alzheimer disease. Neuropsychology. 2018;32(4):401-9.

52 Nordstrom A, Nordstrom P. Traumatic brain injury and the risk of dementia diagnosis: a nationwide cohort study. PLoS Med. 2018; 15(1):e1002496.

53 Gardner RC, Burke JF, Nettiksimmons J, Kaup A, Barnes DE, Yaffe K. Dementia risk after traumatic brain injury vs nonbrain trauma: the role of age and severity. JAMA Neurol. 2014;71(12): 1490-7.

54 Barnes DE, Kaup A, Kirby KA, Byers AL, Diaz-Arrastia R, Yaffe K. Traumatic brain injury and risk of dementia in older veterans. Neurology. 2014;83(4):312-9.

55 Nordstrom P, Michaelsson K, Gustafson Y, Nordstrom A. Traumatic brain injury and young onset dementia: a nationwide cohort study. Ann Neurol. 2014;75(3):374-81.

56 Lee YK, Hou SW, Lee CC, Hsu CY, Huang YS, $\mathrm{Su}$ YC. Increased risk of dementia in patients with mild traumatic brain injury: a nationwide cohort study. PLoS One. 2013;8(5): e62422.

57 Wang HK, Lin SH, Sung PS, Wu MH, Hung KW, Wang LC, et al. Population based study on patients with traumatic brain injury suggests increased risk of dementia. J Neurol Neurosurg Psychiatry. 2012;83(11): 1080-5. 
58 Luukinen H, Viramo P, Herala M, Kervinen K, Kesaniemi YA, Savola O, et al. Fall-related brain injuries and the risk of dementia in elderly people: a population-based study. Eur J Neurol. 2005;12(2):86-92.

59 Nemetz PN, Leibson C, Naessens JM, Beard M, Kokmen E, Annegers JF, et al. Traumatic brain injury and time to onset of Alzheimer's disease: a population-based study. Am J Epidemiol. 1999;149(1):32-40.

60 Cations M, Draper B, Low LF, Radford K, Trollor J, Brodaty H, et al. Non-genetic risk factors for degenerative and vascular young onset dementia: results from the INSPIRED and KGOW studies. J Alzheimers Dis. 2018; 62(4):1747-58.

61 Mendez MF, Paholpak P, Lin A, Zhang JY, Teng E. Prevalence of traumatic brain injury in early versus late-onset alzheimer's disease. J Alzheimers Dis. 2015;47(4):985-93.

62 Abrahamson EE, Ikonomovic MD. Brain injury-induced dysfunction of the blood brain barrier as a risk for dementia. Exp Neurol. 2020;328:113257.

63 Barkhoudarian G, Hovda DA, Giza CC. The molecular pathophysiology of concussive brain injury: an update. Phys Med Rehabil Clin N Am. 2016;27(2):373-93.
64 Frantseva M, Perez Velazquez JL, Tonkikh A, Adamchik Y, Carlen PL. Neurotrauma/neurodegeneration and mitochondrial dysfunction. Prog Brain Res. 2002;137:171-6.

65 Yi JH, Hazell AS. Excitotoxic mechanisms and the role of astrocytic glutamate transporters in traumatic brain injury. Neurochem Int. 2006;48(5):394-403.

66 Franz CK, Joshi D, Daley EL, Grant RA, Dalamagkas $\mathrm{K}$, Leung A, et al. Impact of traumatic brain injury on amyotrophic lateral sclerosis: from bedside to bench. J Neurophysiol. 2019;122(3):1174-85.

67 Maroon JC, Winkelman R, Bost J, Amos A, Mathyssek C, Miele V. Chronic traumatic encephalopathy in contact sports: a systematic review of all reported pathological cases. PLoS One. 2015;10(2):e0117338.

68 Smith DH, Johnson VE, Stewart W. Chronic neuropathologies of single and repetitive TBI: substrates of dementia? Nat Rev Neurol. 2013; 9(4):211-21.

69 Faden AI, Loane DJ. Chronic neurodegeneration after traumatic brain injury: Alzheimer disease, chronic traumatic encephalopathy, or persistent neuroinflammation? Neurotherapeutics. 2015;12(1):143-50.

70 Qian L, Flood PM, Hong JS. Neuroinflammation is a key player in Parkinson's disease and a prime target for therapy. J Neural Transm. 2010;117(8):971-9.
71 Sayed N, Culver C, Dams-O'Connor K, Hammond F, Diaz-Arrastia R. Clinical phenotype of dementia after traumatic brain injury. J Neurotrauma. 2013;30(13):1117-22.

72 Shively S, Scher AI, Perl DP, Diaz-Arrastia R. Dementia resulting from traumatic brain injury: what is the pathology? Arch Neurol. 2012;69(10):1245-51.

73 Blennow K, Brody DL, Kochanek PM, Levin $\mathrm{H}$, McKee A, Ribbers GM, et al. Traumatic brain injuries. Nat Rev Dis primers. 2016;2: 16084.

74 Blennow K, Hardy J, Zetterberg H. The neuropathology and neurobiology of traumatic brain injury. Neuron. 2012;76(5):886-99.

75 Deutsch MB, Mendez MF, Teng E. Interactions between traumatic brain injury and frontotemporal degeneration. Dement Geriatr Cogn Disord. 2015;39(3-4):143-53.

76 Mortimer JA, van Duijn CM, Chandra V, Fratiglioni L, Graves AB, Heyman A, et al. Head trauma as a risk factor for Alzheimer's disease: a collaborative re-analysis of casecontrol studies. EURODEM Risk Factors Research Group. Int J Epidemiol. 1991;20(Suppl 2):S28-35.

77 Fleminger S, Oliver DL, Lovestone S, RabeHesketh S, Giora A. Head injury as a risk factor for Alzheimer's disease: the evidence 10 years on; a partial replication. J Neurol Neurosurg Psychiatry. 2003;74(7):857-62. 